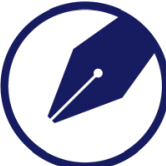

UNIVERSAL WISER

PUBLISHER

\title{
Gas-Phase Ion Exchange into Zeolites: A Proposed Set-Up Design
}

\section{Faouzi Ayaria*, Emna Manneia}

University of Monastir, Faculty of Pharmacy of Monastir, Laboratory of chemical, galenic and pharmacological development of drugs, 5000 Monastir, Tunisia

E-mail: faouzi.ayari@fphm.rnu.tn

\begin{abstract}
The aqueous and solid-state ionic exchanges are widely used for introducing chromium ions into ZSM-5 zeolite $(\mathrm{Si} / 2 \mathrm{Al}=30$ and 50$)$. However, along with their benefits, these exchange methods presented some disadvantages, essentially related to the wasted chemicals. As alternative, we investigated the exchange of Cr and Mo ions into ZSM-5 zeolite by conventional sublimation. Unfortunately, this method exhibited many constraints which were essentially related to the discrepancy between the exchange and the sublimation temperature values $\left(T_{\text {exch }}\right.$ and $T_{\text {sub }}$, respectively). In this work, we proposed a general design of an experimental set-up required for introducing metallic ions into zeolites regardless $T_{\text {exch }}$ and $T_{\text {sub }}$ values. Technically, the implementation of the proposed set-up requires two tubular furnaces, two temperature regulators and a linear reactor.
\end{abstract}

Keywords: Apparatus design, ion exchange, sublimation, zeolite, furnace

\section{Introduction}

Zeolites are currently attracting substantial attention on the laboratory scale due to their huge technological potential in catalytic, adsorption and ion-exchange processes ${ }^{[1,2]}$. Among them, MFI, BEA, MOR, and FAU zeolites are basic and typical catalysts ${ }^{[3,4]}$. Following ion exchange, $\mathrm{Na}^{+}$ions in the framework are substituted by $\mathrm{H}^{+}$to form protonated zeolite, which offers interesting catalytic properties in many reactions. On the other hand, the zeolites are often modified by introducing $f$ - and $d$-block metal ions, and good catalytic activities are achieved in different reactions ${ }^{[5-9]}$.

Basically, the conventional aqueous exchange (AEx) is described in Eq. 1, where, for the sake of simplicity, a metal chloride is used ${ }^{[10]}$.

$$
\begin{aligned}
& a\left[\mathrm{M}\left(\mathrm{OH}_{2}\right)_{w}\right]^{\mathrm{n}+}+\mathrm{n} a \mathrm{Cl}^{-}+b \mathrm{NaZ} \leftrightarrow \\
& x \mathrm{MZ}_{\mathrm{n}}+(a-x)\left[\mathrm{M}\left(\mathrm{OH}_{2}\right)_{w}\right]^{\mathrm{n}+}+\mathrm{n} a \mathrm{Cl}^{-}+\mathrm{n} x \mathrm{Na}^{+}+(b-\mathrm{n} x) \mathrm{NaZ}
\end{aligned}
$$

Here, $\mathrm{M}$ is an $\mathrm{n}$-valent metal cation and $\mathrm{Z}$ is a mono-valent zeolite fragment (ion exchange site) ${ }^{[10]}$.

Such an exchange method, which consists on the handling of large quantities of electrolyte solution, often suffered from many issues due to thermodynamic and kinetic constraints. Indeed, one has to repeatedly perform the exchange procedure in order to obtain a high ion exchange degree ${ }^{[10]}$. On the other hand, the zeolites exhibit an alkaline reaction in aqueous medium (Eq. 2), and in the presence of many transition metal cations, basic salts may be precipitated ${ }^{[11]}$.

$$
\mathrm{Na}^{+}{ }_{\text {(zeolite) }}+2 \mathrm{H}_{2} \mathrm{O} \rightarrow \mathrm{Na}^{+}{ }_{\text {(solution) }}+\mathrm{H}_{3} \mathrm{O}^{+}{ }_{\text {(zeolite) }}+\mathrm{OH}^{-} \text {(solution) }
$$

The solid-state ionic exchange (SSIEx) is an alternative route to the preparation of zeolite-based catalysts ${ }^{[12-14]}$. As its name indicates, the SSIEx involves the exchange of ions between two solids with little or no water present (Eqs. 3 and 4 ):

$$
\begin{aligned}
& \mathrm{MCl}_{\mathrm{n}}+\mathrm{n} \mathrm{NaZ} \rightarrow x \mathrm{MZ}_{\mathrm{n}}+(1-x) \mathrm{MCl}_{\mathrm{n}}+(\mathrm{n}-\mathrm{n} x) \mathrm{NaZ}+\mathrm{n} x \mathrm{NaCl} \rightarrow \mathrm{MZ}_{\mathrm{n}}+\mathrm{n} \mathrm{NaCl} \\
& \mathrm{MCl}_{\mathrm{n}}+\mathrm{n} \mathrm{HZ} \rightarrow x \mathrm{MZ}_{\mathrm{n}}+(1-x) \mathrm{MCl}_{\mathrm{n}}+(\mathrm{n}-\mathrm{n} x) \mathrm{HZ}+\mathrm{n} x \mathrm{HCl} \uparrow \rightarrow \mathrm{MZ}_{\mathrm{n}}+\mathrm{n} \mathrm{HCl} \uparrow
\end{aligned}
$$


Here, $\mathrm{M}$ is an $\mathrm{n}$-valent metal cation and $\mathrm{Z}$ is a mono-valent zeolite fragment in its sodium-, or $\mathrm{H}^{+}-$form ${ }^{[10]}$.

Specifically, the solid-state ionic exchange method consists on preparing an intimate mixture of the zeolite and the metal salt containing the entering ion. The mixture may be prepared by either intense milling or by suspending both components in an organic solvent, mixing thoroughly and allowing the solvent to evaporate. This is followed by a thermal activation under inert gas or oxygen stream for a couple of hours.

It is important to acknowledge the problems which may arise from the solid-state ionic exchange. In effect, the experimental conditions involved in the SSIEx, e.g. the zeolites' hydration level ${ }^{[4]}$, the nature of carrier gas ${ }^{[4]}$, can have a critical effect on the final metallic distribution. Ignorance of these parameters and consequent failure to choose the proper experimental conditions can lead to meaningless and flawed interpretations.

A more interesting approach for introducing metallic cations into zeolites was found to be the sublimation of a volatile salt, e.g. $\mathrm{CoCl}_{2(\mathrm{cr})}{ }^{[15,16]}, \mathrm{CoBr}_{2(\mathrm{cr})}{ }^{[16]}, \mathrm{FeCl}_{3(\mathrm{cr})}{ }^{[17,18]}, \mathrm{CuCl}_{(\mathrm{cr})}{ }^{[19]}, \mathrm{InCl}_{(\mathrm{cr})}{ }^{[20]}, \mathrm{MoCl}_{5(\mathrm{cr})}{ }^{[21]}$ and $\mathrm{Mo}(\mathrm{CO})_{6(\mathrm{cr})}{ }^{[4,22]}$, in contact with the zeolite under a continuous circulation of carrier gas. From a practical point of view, performing the exchange by sublimation (denoted also as chemical vapour deposition, CVD) cuts down on the costs of wasted chemicals as a wide range of chemical precursors (halides, hydrides, organometallics, etc.) can be used.

There are many publications on the subject of sublimation that include books ${ }^{[23,24]}$, review articles ${ }^{[25,26]}$ as well as journals ${ }^{[27]}$. Krishna et al. ${ }^{[27]}$ introduced $\mathrm{FeCl}_{3}$ into $\mathrm{H}^{+} / \mathrm{ZSM}-5$ zeolite by sublimation. In their experimental protocol, the authors ${ }^{[27]}$ placed the zeolite powder between two quartz wool plugs inside a $U$-shaped quartz reactor and the metallic precursor (anhydrous $\mathrm{FeCl}_{3}$ ) inside a glass vial. The reactor inlet was connected to the carrier gas flow $\left(\mathrm{He}, 10^{-1} \mathrm{dm}^{3} \mathrm{~min}^{-1}\right)$ throughout a flexible plastic tube, while the exit was connected to the exhaust.

It is worth to note that the glass vial was, firstly, corrugated from one end, and then correctly placed inside the flexible plastic tube in order to assure continuous circulation of the carrier gas ${ }^{[27]}$. Prior the thermal treatment, the $U$-shaped quartz reactor was placed inside a programmable furnace, while the glass vial was kept outside the furnace (the corrugated end facing the zeolite). Thereafter, upon a thermal treatment performed at $873 \mathrm{~K}$ for 2 hours under helium stream, the corrugated end of the glass vial was broken and $\mathrm{FeCl}_{3}$ fell on the quartz wool placed above the zeolite sample (check Figure 1 in reference ${ }^{[27]}$ ).

The exchange of gaseous salts into the zeolite may result in a non-uniform loading in larger scale preparations. Therefore, the use of a sophisticated reactor and/or vacuum system by CVD variants such as low pressure or ultrahigh vacuum CVD, plasma assisted CVD and photo-assisted CVD tends to increase the cost of fabrication ${ }^{[26]}$.

First of all, and especially referring to zeolites, we will address the long-standing issues related to solid-state ionic exchange and aqueous exchange. Secondly, we will shed light on the conventional sublimation method. Thirdly, we consider the design of a set-up involving the introduction of metallic ions into zeolites regardless the exchange and the sublimation temperature values.

\section{Experimental}

In this work, we used $\mathrm{NH}_{4}^{+} / \mathrm{ZSM}-5(\mathrm{Si} / 2 \mathrm{Al}=30 ; 50$ and 80$), \mathrm{NH}_{4}^{+} /$mordenite $(\mathrm{Si} / 2 \mathrm{Al}=20), \mathrm{H}^{+} / \mathrm{USY}(\mathrm{Si} / 2 \mathrm{Al}=30)$ and $\mathrm{NH}_{4}^{+} / \mathrm{Y}(\mathrm{Si} / 2 \mathrm{Al}=5.1)$ zeolites. The inorganic salts, i.e. $\mathrm{Cr}^{\mathrm{III}}$ acetate, $\mathrm{Cr}^{\mathrm{III}}$ nitrate, $\mathrm{Cr}^{\mathrm{III}}$ sulphate, ammonium dichromate, $\mathrm{Cr}^{\mathrm{III}}$ chloride and $\mathrm{Mo}^{\mathrm{V}}$ chloride were used without further purification.

\subsection{Preparation of $\mathrm{Cr} /$ zeolite mechanical mixtures}

The dry mixtures were prepared by intense milling the ZSM-5 zeolite and the inorganic salt in an agate mortar for few minutes. The theoretical $\mathrm{Cr} / \mathrm{Al}$ molar ratio was fixed at 1 based on the empirical formula of zeolite. The mixtures were labelled as Cr-P-ZSM-(Si/2Al). P stands for acetate, ammonium dichromate, chloride, nitrate and sulphate.

\subsection{Preparation of Cr-containing samples}

For solid-state ionic exchange, the samples were prepared by intensively milling the ZSM-5 zeolite $(\mathrm{Si} / 2 \mathrm{Al}=30)$ and the inorganic salt $(\mathrm{Cr} / \mathrm{Al}=1)$ in an agate mortar for few minutes. The powder was then heated under helium for 12 hours $(2$ $\left.\mathrm{K} \min ^{-1}\right)$ at $773 \mathrm{~K}\left(3 \times 10^{-2} \mathrm{dm}^{3} \mathrm{~min}^{-1}\right)$. The obtained samples were labelled as Cr-P-SSIEx.

For aqueous exchange, the ZSM-5 zeolite $(\mathrm{Si} / 2 \mathrm{Al}=50)$ was exchanged in three consecutive steps by using a metallic solution $\left(10^{-2} \mathrm{M}, 1 \times 10^{-1} \mathrm{dm} 3 \mathrm{~g}^{-1}\right)$ between 343 and $353 \mathrm{~K}$ for 24 hours. After each exchange, the solution was centrifuged $\left(1100 \mathrm{~min}^{-1}\right)$ during 20 minutes and the sample was washed with de-ionized water. After the third exchange, the sample was dried at $383 \mathrm{~K}$ and then treated under helium at $773 \mathrm{~K}$ for 3 hours $\left(3 \times 10^{-2} \mathrm{dm}^{3} \mathrm{~min}^{-1}\right.$, heating rate $\left.2 \mathrm{~K} \mathrm{~min}^{-1}\right)$. The samples were labelled as Cr-P-AEx.

For the conventional sublimation method, the zeolite was heated under vacuum for 4 hours at room temperature and 
subsequently introduced in a $U$-shaped quartz reactor as can be visualized in Figure 1.

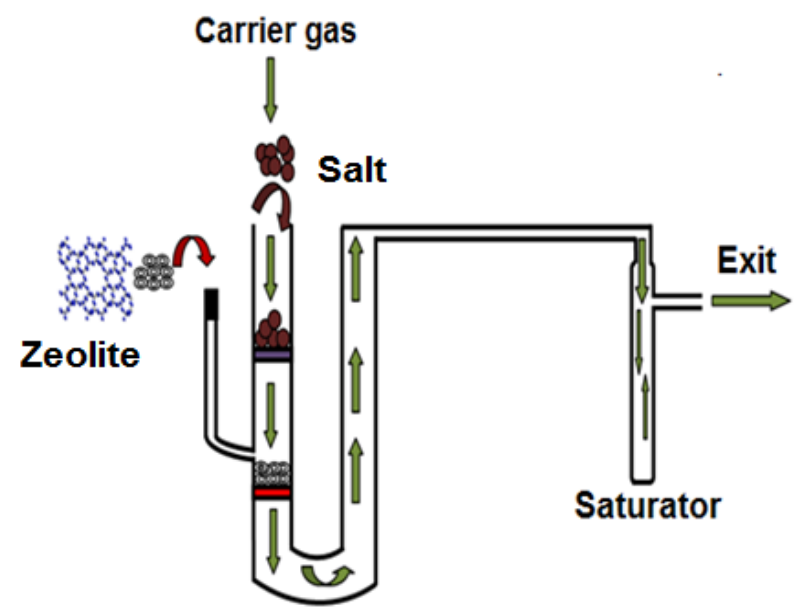

Figure 1. Conventional sublimation reactor

The reactor was placed inside a programmable furnace before adding the desired amount of salt. It is worth to note that the reactor inlet was connected to the carrier gas flow, while the exit was connected to a saturator. The reactor was then heated up to a particular temperature and maintained at this temperature for several hours.

\subsection{Characterization}

The X-ray photoelectron spectroscopy (XPS) analyses were performed on a SSX 100/206 photoelectron spectrometer from Surface Science Instruments (USA) equipped with a monochromatized microfocused Al X-ray source (1486.6 $\mathrm{eV}$, powered at $20 \mathrm{~mA}$ and $10 \mathrm{kV}$ ). Before analyses, the powders were pressed in small stainless steel troughs of $4 \mathrm{~mm}$ diameter and were placed on an aluminium conductive carousel. The $\mathrm{C}-(\mathrm{C}, \mathrm{H})$ component of the $\mathrm{C} 1 s$ peak of carbon had been fixed to $284.8 \mathrm{eV}$ to set the binding energy scale. Data treatment was performed with the Casa XPS program (Casa Software Ltd., UK). Some Cr2 $p$ peaks were decomposed into several doublets taking into account that the theoretical distance between $\mathrm{Cr} 2 p 1 / 2$ and $\mathrm{Cr} 2 p 3 / 2$ peaks is $9.8 \mathrm{eV}$ and the area ratio is $2 / 3$. The energy-dispersive $\mathrm{X}$-ray spectroscopy (EDX) was performed with a JEOL-JEM 2100F instrument (X-MAX detector, accelerating voltage of $200 \mathrm{kV}$ and energy resolution of $20 \mathrm{eV}$ ). The thermal analysis was executed using a Labsys/Setaram TG-DSC 111 apparatus under air stream $\left(5 \times 10^{-2} \mathrm{dm}^{3} \mathrm{~min}^{-1}\right)$ between room temperature and $1050 \mathrm{~K}$ at a heating rate of $10 \mathrm{~K} \mathrm{~min}^{-1}$. The $\mathrm{pH}$-metric measurements were performed with an adwa AD 1020 apparatus.

\section{Results and discussion}

\subsection{Disadvantages of aqueous exchange}

The zeolite hydrolysis would give rise to a large number of impurity species which modify the $\mathrm{pH}$ of the solution. In our study, the hydrolysis was performed by mixing 1 gram of ZSM-5 zeolite in $5 \times 10^{-2} \mathrm{dm}^{3}$ of water for 4 hours. The zeolite was then separated by centrifugation (1100 $\mathrm{min}^{-1}$ for 1 hour) and the aqueous phase was recuperated. The $\mathrm{pH}$ of the solution was measured and the results are compiled in Table 1.

Table 1. Zeolite hydrolysis: Final $\mathrm{pH}$ as a function of $\mathrm{Si} / 2 \mathrm{Al}$ ratio

\begin{tabular}{ll}
\hline Sample & $\mathrm{pH}$ \\
\hline $\mathrm{H}_{2} \mathrm{O}($ reference $)$ & 5.91 \\
$\mathrm{NH}_{4}^{+} / \mathrm{ZSM}-5(\mathrm{Si} / 2 \mathrm{Al}=30)$ & 6.71 \\
$\mathrm{NH}_{4}^{+} / \mathrm{ZSM}-5(\mathrm{Si} / 2 \mathrm{Al}=50)$ & 6.07 \\
$\mathrm{NH}_{4}^{+} / \mathrm{ZSM}-5(\mathrm{Si} / 2 \mathrm{Al}=80)$ & 5.63 \\
\hline
\end{tabular}


It can be deduced from Table 1 that the $\mathrm{pH}$ measurements correspond to a marked alkalinity, which could be ascribed to the equilibrium:

$$
\mathrm{NH}_{4}^{+} / \mathrm{ZSM}-5+\mathrm{H}_{2} \mathrm{O}=\mathrm{H}^{+} / \mathrm{ZSM}-5+\mathrm{NH}_{4}^{+}, \mathrm{OH}^{-}
$$

Apparently, the higher the amount of aluminium forming part of the framework, the greater the number of ammonium ions initially present in the zeolite. Consequently, the hydrolysis degree increases with a declining $\mathrm{Si} / 2 \mathrm{Al}$ ratio. This systematic trend has been experimentally observed for trace level exchange of calcium ions in zeolites $\mathrm{X}$ and $\mathrm{Y}{ }^{[28,29]}$ as well as for caesium exchange in synthetic mordenite ${ }^{[30]}$.

In the case of $\mathrm{NH}_{4}^{+} / \mathrm{ZSM}-5(\mathrm{Si} / 2 \mathrm{Al}=80)$, the $\mathrm{pH}$ value is lower than the one recorded with pure $\mathrm{H}_{2} \mathrm{O}$. Due to the presence of low aluminium quantity, the dissolution of acidic gases present in the atmosphere (e.g. $\left.\mathrm{CO}_{2}\right) \mathrm{decreases}$ the $\mathrm{pH}$ of the solution.

The alkaline reaction (Eq. 5) may lead to other secondary phenomena. In effect, some metallic ions $\left(\mathrm{M}^{\mathrm{n}+}\right)$ can be precipitated according to Eq. 6.

$$
\mathrm{M}^{\mathrm{n}+}+\mathrm{OH}^{-} \rightarrow \mathrm{M}(\mathrm{OH}) n
$$

The solubility product $\left(\mathrm{K}_{\mathrm{s}}\right)$ is given by Eq. 7 .

$$
\mathrm{K}_{\mathrm{s}}(\mathrm{T})=\left[\mathrm{M}^{n+}\right] \times\left[\mathrm{OH}^{-}\right]^{n}=\left[\mathrm{M}^{n+}\right] \times\left(\frac{\mathrm{Ke}}{\left[\mathrm{H}^{+}\right]}\right)^{n}
$$

$\mathrm{K}_{\mathrm{e}}(\mathrm{T})$ is the ionic product of $\mathrm{H}_{2} \mathrm{O}(=14$ at $298.15 \mathrm{~K})$. Therefore:

$$
\mathrm{pH}=14-\frac{1}{n}\left(\mathrm{pK}_{\mathrm{s}}+\log \left[\mathrm{M}^{n+}\right]\right)
$$

The $\mathrm{pH}$ at which the $\mathrm{M}^{n+}$ precipitates depends essentially on the $\mathrm{K}_{\mathrm{s}}$ and $n$ values. For example, $\mathrm{Ni}^{2+}$ at $10^{-1} \mathrm{M}^{-1}$ precipitates at $\mathrm{pH}=6.45\left(\mathrm{~K}_{\mathrm{s}}\left(\mathrm{Ni}(\mathrm{OH})_{2(\mathrm{rr})}\right)=7.94 \times 10^{-17}\right.$ at $\left.298.15 \mathrm{~K}^{[31]}\right)$ and, as a matter of fact, the solution would contain $\mathrm{Ni}(\mathrm{OH})_{2(\mathrm{cr})}$ during aqueous exchange into $\mathrm{ZSM}-5$ zeolite $(\mathrm{Si} / 2 \mathrm{Al}=30)$. It is judicious therefore to choose the appropriate concentration of $\mathrm{M}^{n+}$ and the temperature values in order to avoid the precipitation.

\subsection{Comparison between aqueous exchange and SSIEx}

According to Eq. 8, the precipitation of $\mathrm{Cr}^{3+}\left(10^{-2} \mathrm{M}\right)$ into $\mathrm{Cr}(\mathrm{OH})_{3(\mathrm{cr})}$ occurs at $\mathrm{pH}=4.61\left(\mathrm{~K}_{\mathrm{s}}\left(\mathrm{Cr}(\mathrm{OH})_{3(\mathrm{cr})}\right)=6.44 \times\right.$ $10^{-31}$ at $\left.298.15 \mathrm{~K}^{[32]}\right)$. In order to increases the solubility of $\mathrm{Cr}(\mathrm{OH})_{3(\mathrm{cr})}$, we performed the aqueous exchange of $\mathrm{Cr}^{3+}$ into ZSM-5 zeolite $(\mathrm{Si} / 2 \mathrm{Al}=50)$ between 343 and $353 \mathrm{~K}$.

The XPS and EDX results obtained with samples issued from aqueous exchange and solid-state ionic exchange methods using Cr nitrate and acetate are compiled in Tables 2 and 3, while Figure 2 represents the XPS spectrum of the sample prepared by AEx using Cr nitrate.

Table 2. XPS results of samples prepared by solid-state ionic exchange and aqueous exchange using $\mathrm{Cr}$ nitrate and $\mathrm{Cr}$ acetate

\begin{tabular}{lcccc}
\hline & Cr-nitrate-AEx & Cr-acetate-AEx & Cr-nitrate-SSIEx & Cr-acetate-SSIEx \\
\hline & & Atomic surface concentration (\%) & \\
$\mathrm{Cr} 2 p$ & 0.32 & 0.49 & 0.54 & 0.64 \\
$\mathrm{Si} 2 p$ & 27.0 & 29.0 & 30.4 & 30.1 \\
$\mathrm{~A} 12 p$ & 1.05 & 1.73 & 0.88 & 0.89 \\
& & & \\
$\mathrm{Cr} / \mathrm{Si}$ & 0.012 & Atomic surface ratio & 0.021 \\
$\mathrm{~A} 1 / \mathrm{Si}$ & 0.039 & 0.017 & 0.018 & 0.030 \\
$\mathrm{Cr} / \mathrm{Al}$ & 0.31 & 0.060 & 0.029 & 0.70 \\
& & 0.28 & 0.62 & 580.0 \\
$\mathrm{Cr} 2 p 3 / 2\left(\mathrm{Cr}^{6+}\right)$ & 580.0 & Binding energy (eV) & 576.5 \\
$\mathrm{Cr} 2 p 3 / 2\left(\mathrm{Cr}^{3+}\right)$ & 576.0 & 580.0 & 580.0 & 104.2 \\
$\mathrm{Si} 2 p$ & 103.4 & 576.3 & 576.7 & 75.3 \\
$\mathrm{~A} 12 p$ & 74.5 & 103.6 & 104.1 & 75.4 \\
\hline
\end{tabular}


Table 3. EDX results

\begin{tabular}{lcccc}
\hline Sample & $\mathrm{Al}($ wt. \%) & $\mathrm{Si}($ wt. \%) & $\mathrm{O}($ wt. \%) & Cr $($ wt. \%) \\
\hline $\mathrm{NH}_{4}{ }^{+} / \mathrm{ZSM}-5(\mathrm{Si} / 2 \mathrm{Al}=50)$ & 1.46 & 41.53 & 56.93 & - \\
Cr-acetate-AEx & 1.39 & 45.74 & 52.20 & $0.61 ; 0.61 ; 0.61 ; 0.82$ \\
Cr-nitrate-AEx & 1.49 & 45.07 & 53.05 & $0.11 ; 0.18 ; 0.11 ; 0.06$ \\
Cr-acetate-SSIEx & 1.25 & 49.57 & 46.85 & $2.62 ; 1.92 ; 1.11,3.64$ \\
Cr-nitrate-SSIEx & 2.21 & 45.12 & 46.29 & $3.90 ; 2.89 ; 16.51 ; 2.20$ \\
\hline
\end{tabular}

$\mathrm{a}:$ Average value of four individual points at the surface, ${ }^{\mathrm{b}}:$ Determined by EDX in four individual points at the surface

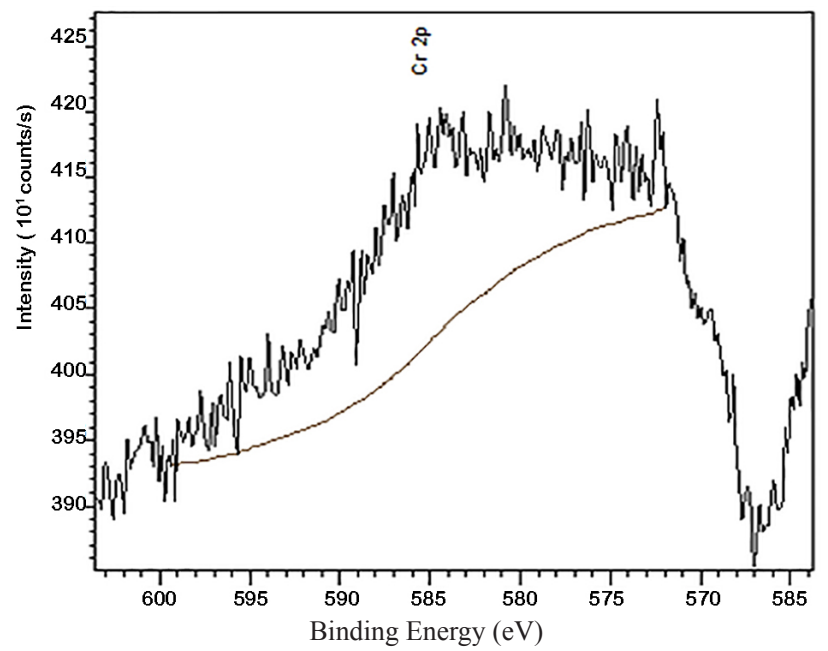

Figure 2. XPS spectrum of Cr-nitrate-AEx, i.e. the sample prepared by aqueous exchange using $\mathrm{NH}_{4}^{+} / \mathrm{ZSM}-5$ zeolite $(\mathrm{Si} / \mathbf{2 A l}=\mathbf{5 0})$ and $\mathrm{Cr}$ nitrate

According to Tables 2 and 3, the samples issued from aqueous exchange contained low amounts of chromium at the surface (check the $\mathrm{Cr} / \mathrm{Al}$ ratios and Figure 2). On the other hand, the data compiled in both tables also indicate that the surfaces of the samples obtained from SSIEx contain higher amounts of chromium (16.51 wt. \% for Cr-nitrate-SSIEx sample) than those prepared by AEx. Apparently, the size of $\left[\mathrm{Cr}\left(\mathrm{OH}_{2}\right)_{6}\right]^{3+}$ complex is too high to diffuse, during aqueous exchange, throughout the ZSM-5 channels (dimensionality: $(5.3 \times 5.6) \AA$ and $\left.(5.1 \times 5.5) \AA \AA^{[21]}\right)$.

\subsection{Disadvantages of solid-state ionic exchange}

\subsubsection{Effect of the nature of salt and $\mathrm{Si} / 2 \mathrm{Al}$ ratio}

In Figure 3, we illustrated the thermogravimetry and differential scanning calorimetry (TG/DSC) curves of pure (Figure $3 \mathrm{~A}$ ) and mixed (Figuer 3B and 3C) Cr sulphate recorded under air stream $\left(5 \times 10^{-2} \mathrm{dm}^{3} \min ^{-1}, 10 \mathrm{~K} \mathrm{~min}{ }^{-1}\right)$. 

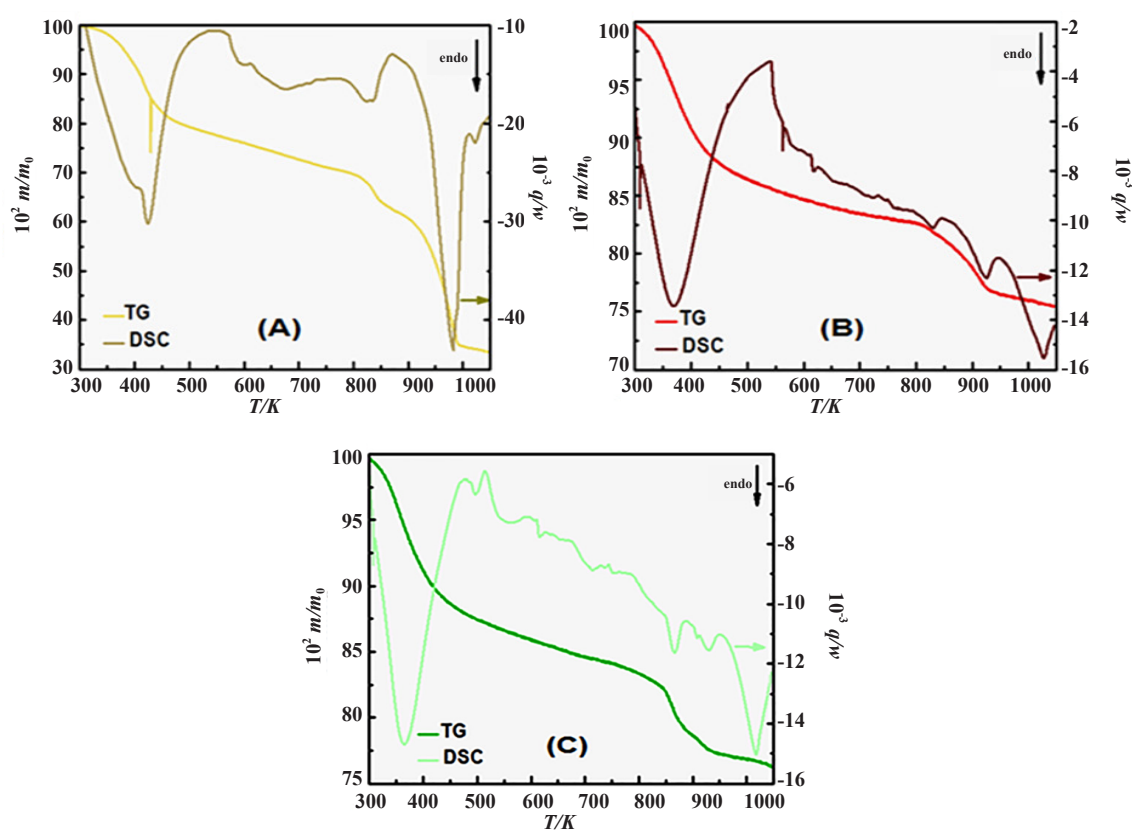

Figure 3. Thermal treatment of $\mathrm{Cr}$ sulphate $\left(\mathrm{Cr}_{2}\left(\mathrm{SO}_{4}\right)_{3} \cdot 9 \mathrm{H}_{2} \mathrm{O}\right)$ under air stream $\left.\left(5 \times 10^{-2} \mathrm{dm}^{3} \mathrm{~min}^{-1}, 10 \mathrm{~K} \mathrm{~min}\right)^{-1}\right)$ : TG/DSC curves of $(\mathrm{A})$ pure $\mathrm{Cr}$ sulphate, (B) Cr-sulphate-ZSM-(30) (28.3 wt. \% of salt), and (C) Cr-sulphate-ZSM-(50) (16.6 wt. \% of salt) $q$ : Heat flow

According to Figure 3A, the total decomposition of $\mathrm{Cr}$ sulphate requires a very high temperature $(\sim 980 \mathrm{~K})$. Nevertheless, the reaction of $\mathrm{Cr}$ sulphate and the zeolite occurred between 800 and $950 \mathrm{~K}$ whatever the $\mathrm{Si} / 2 \mathrm{Al}$ ratio (Figure $3 \mathrm{~B}$ and $3 \mathrm{C})$.

In Figure 4, we reported the TG/DSC curves of $\mathrm{Cr}$ acetate, ammonium dichromate, $\mathrm{Cr}$ chloride and $\mathrm{Cr}$ nitrate treated under air stream $\left(5 \times 10^{-2} \mathrm{dm}^{3} \mathrm{~min}^{-1}, 10 \mathrm{~K} \mathrm{~min}^{-1}\right)$. Likewise, in Figure S1, we reported the TG/DSC curves of Cr-P-ZSM$(\mathrm{Si} / 2 \mathrm{Al})$ mixtures treated under air stream $\left(5 \times 10^{-2} \mathrm{dm}^{3} \mathrm{~min}^{-1}, 10 \mathrm{~K} \mathrm{~min}{ }^{-1}\right)$.
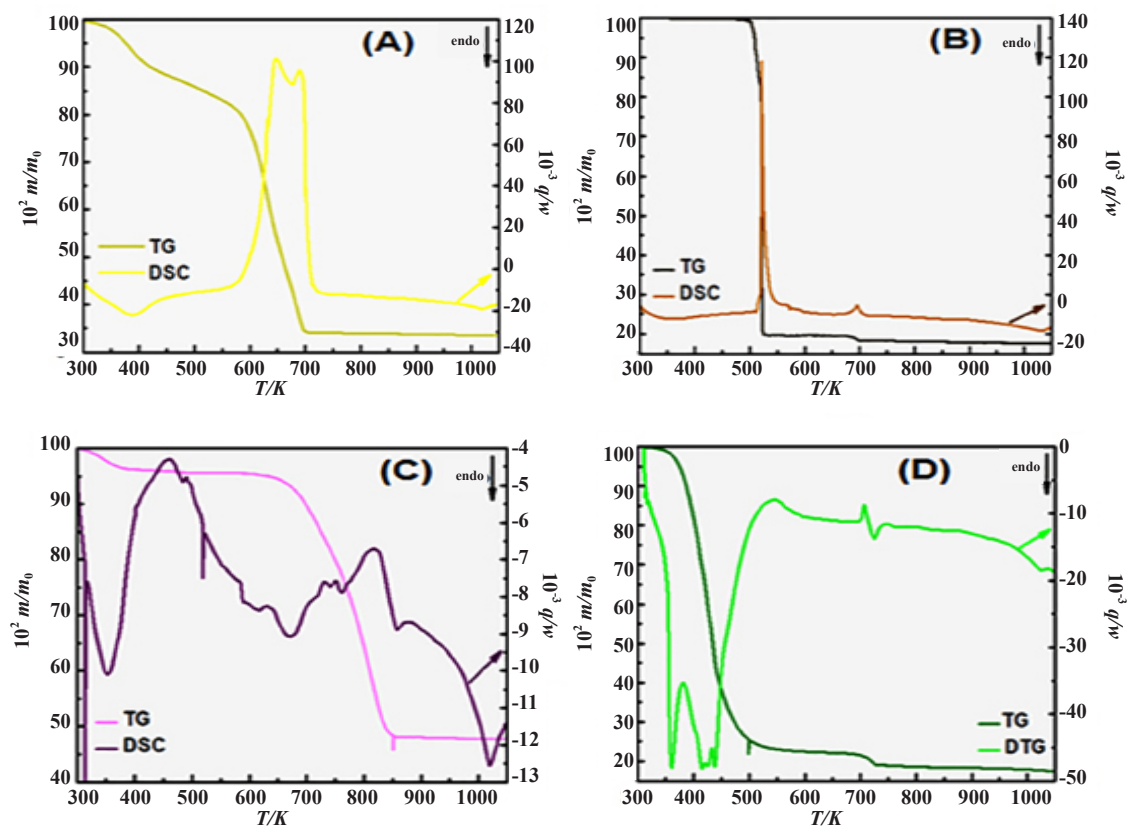

Figure 4. TG/DSC curves of pure (A) Cr acetate $\left(\mathrm{Cr}_{3}(\mathrm{OH})_{2}\left(\mathrm{OOCCH}_{3}\right)_{7}\right),(\mathrm{B})$ ammonium dichromate $\left(\left(\mathrm{NH}_{4}\right)_{2} \mathrm{Cr}_{2} \mathrm{O}_{7}\right)$, (C) Cr chloride $\left(\mathrm{CrCl}_{3}\right)$, and (D) $\mathrm{Cr}$ nitrate $\left(\mathrm{Cr}\left(\mathrm{NO}_{3}\right)_{3} \cdot 9 \mathrm{H}_{2} \mathrm{O}\right)$ treated under air stream $\left(5 \times 10^{-2} \mathrm{dm}^{3} \mathrm{~min}^{-1}, 10 \mathrm{~K} \mathrm{~min}{ }^{-1}\right)$ $q$ : Heat flow 
Our thermal analyses focus also on the interaction developed between the different $\mathrm{Cr}$ precursors and the zeolites. A proposed measure of the interaction strength is $\alpha$-parameter ${ }^{[33]}$ which is defined as:

$$
\alpha=\frac{\% \mathrm{WL}_{\mathrm{s}}}{\% \mathrm{WL}_{\mathrm{uns}}} \times 100
$$

Here, $\mathrm{WL}_{\mathrm{uns}}$ is the total mass loss observed with unsupported $\mathrm{Cr}$ salts, while $\mathrm{WL}_{\mathrm{s}}$ is the total mass loss observed upon the treatment of Cr-P-ZSM-(Si/2Al) mixtures.

The results obtained with pure ammonium dichromate, $\mathrm{Cr}$ acetate, $\mathrm{Cr}$ chloride, $\mathrm{Cr}$ nitrate, $\mathrm{Cr}$ sulphate and Cr-P-ZSM(Si/2Al) mixtures are compiled in Table 4.

\begin{tabular}{lccc}
\multicolumn{4}{l}{ Table 4. The different mass losses and $\alpha$-parameter for several (un)supported chromium salts } \\
\hline Mixture & $\mathrm{WL}_{\text {uns }}(\%)$ & $\mathrm{WL}_{\mathrm{s}}(\%)$ & $\alpha(\%)$ \\
\hline Ammonium dichromate & 82.33 & - & - \\
Cr-ammonium dichromate-ZSM-(30) & - & 15.10 & 18.34 \\
Cr acetate & 66.46 & - & - \\
Cr-acetate-ZSM-(30) & - & 22.37 & 33.66 \\
Cr-acetate-ZSM-(50) & - & 15.66 & 23.56 \\
Cr chloride & 51.38 & - & - \\
Cr-chloride-ZSM-(30) & - & 23.40 & 45.54 \\
Cr nitrate & 87.72 & - & - \\
Cr-nitrate-ZSM-(30) & - & 32.05 & 38.75 \\
Cr-nitrate-ZSM-(50) & - & 27.01 & 32.35 \\
Cr sulphate & 67.23 & - & - \\
Cr-sulfate-ZSM-5-(30) & - & 24.48 & 36.41 \\
Cr-sulfate-ZSM-5-(50) & - & 23.81 & 35.42 \\
\hline
\end{tabular}

According to the data collected in Table 4, the mixtures exhibited different $\alpha$-parameter values, i.e. each salt experiences its own affinity towards the zeolite. The highest $\alpha$-value was recorded with Cr-chloride-ZSM-(30) mixture, while the lowest one belongs to Cr-ammonium dichromate-ZSM-(30). A fortiori, the compatibility of the salt and the zeolite should be taken in consideration before performing the SSIEx by the calculation of $\alpha$-parameter. 


\subsubsection{Effect of temperature on the zeolite structure}

In Figure 5, we depicted the DSC curves of mordenite, Y, ultrastable and ZSM-5 $(\mathrm{Si} / 2 \mathrm{Al}=30$ and 50$)$ zeolites treated under air stream $\left(5 \times 10^{-2} \mathrm{dm}^{3} \mathrm{~min}^{-1}, 10 \mathrm{~K} \mathrm{~min}^{-1}\right)$.

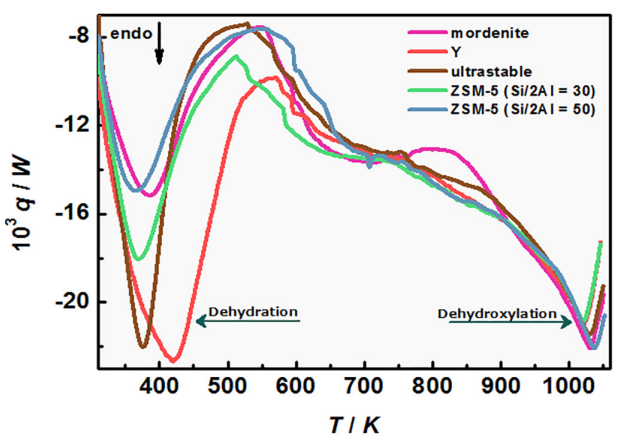

Figure 5. Thermal treatment of different zeolites under helium stream $\left(5 \times 10^{-2} \mathrm{dm}^{3} \mathrm{~min}^{-1}, 10 \mathrm{~K} \mathrm{~min}^{-1}\right)$ : DSC curves $q$ : Heat flow

The obtained results indicate that the zeolites exhibited a dehydration process below $600 \mathrm{~K}$. However, at high temperatures, the dehydroxylation of the zeolites takes place.

During the solid-state ionic exchange, the temperature of the thermal treatment should be optimized in order to avoid the zeolites' dehydroxylation.

\subsection{Disadvantages of conventional sublimation}

The conventional sublimation was performed using the apparatus presented in Figure 1. Firstly, the $\mathrm{NH}_{4}^{+} / \mathrm{ZSM}^{-5}$ zeolite powder $(\mathrm{Si} / 2 \mathrm{Al}=50)$ was dehydrated at $823 \mathrm{~K}$ under $\arg$ on $\left(5 \times 10^{-2} \mathrm{dm}^{3} \mathrm{~min}^{-1}, 3 \mathrm{~K} \mathrm{~min}^{-1}\right)$ for 10 hours. The reactor was then cooled to room temperature and $\mathrm{MoCl}_{5}$ was introduced $(17.00 \mathrm{wt}$. \%). The reactor was later heated under helium to $633 \mathrm{~K}\left(3 \mathrm{~K} \mathrm{~min}^{-1}\right)$ and was kept for 12 hours at this temperature. The same method was used for $\mathrm{CrCl}_{3}(14.30 \mathrm{wt}$. $\%$ of $\mathrm{CrCl}_{3}$ ) thought in this case, the reactor was heated at $773 \mathrm{~K}$ and kept for 12 hours.

Following the thermal treatment, we were unable to exchange $\mathrm{Cr}^{3+}$ into $\mathrm{ZSM}-5$ at $773 \mathrm{~K}$ since $\mathrm{CrCl}_{3}$ sublimates at $1073 \mathrm{~K}$ under helium flow ${ }^{[33]}$. As for the exchange of $\mathrm{MoCl}_{5}$ into zeolite at $633 \mathrm{~K}$, it was also impractical as $\mathrm{MoCl}_{5}$ is decomposed into $\mathrm{MoOCl}_{3}$ and $\mathrm{MoOCl}_{4}$ which sublimate above $586 \mathrm{~K}^{[13]}$ and at the end of experiment, a significant fraction of $\mathrm{MoCl}_{5}$ was transformed into the stable $\mathrm{MoO}_{3}$ (which sublimates at $898 \mathrm{~K}^{[13]}$ ).

\subsection{How to overcome the problems related to conventional sublimation}

As seen above, the conventional sublimation method exhibited many constraints which were essentially related to the discrepancy between the exchange and the sublimation temperature values $\left(T_{\text {exch }}\right.$ and $T_{\text {sub }}$, respectively). As a matter of fact, we proposed a general design of an experimental set-up which allows the introduction of metallic ions into zeolites regardless the $T_{\text {exch }}$ and $T_{\text {sub }}$ values.

\subsubsection{Apparatus description}

The proposed experimental apparatus is presented in Figure 6.

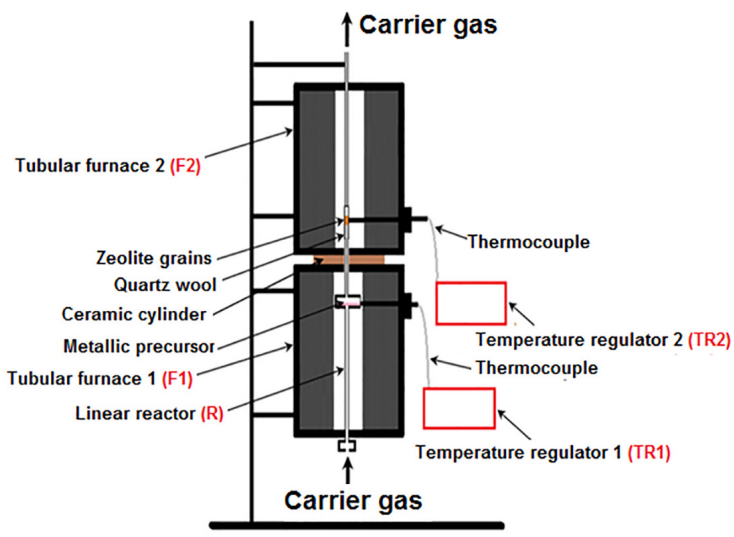

Figure 6. Proposed set-up for non-conventional sublimation 
The apparatus presented in Figure 6 is composed of two tubular furnaces (denoted as F1 and F2) which were placed vertically and maintained by anchors. Each furnace was connected to two temperature regulators (TR1 and TR2). The linear reactor (R), which contains, separately, the zeolite grains and the metallic precursor, was placed horizontally.

The zeolite grains and the metallic salt should be placed inside the linear reactor $(\mathrm{R})$ as demonstrated in Figure 7.

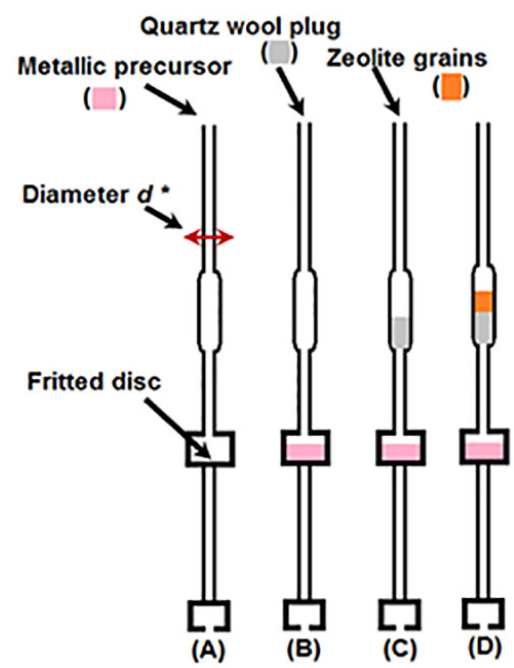

Figure 7. The different steps required for introducing the zeolite and the metallic salt in the reactor: (A) Empty reactor, (B) Metallic salt inside the reactor, (C) Metallic salt and quartz wool plug and metallic salt inside the reactor, and (D) Reactor ready for use (which contains the salt, the quartz wool and the zeolite)

Specifically, the metallic precursor (symbolized by a pink-coloured square in Figure 7) should be placed inside the large section of the reactor, i.e. above the fritted disc. Thereafter, a quartz wool plug (grey-coloured square in Figure 7) should be placed inside the reactor in order to sustain the zeolite grains (orange-coloured square in Figure 7).

In a second step, the tubular furnaces (F1 and F2) should be intensely anchored into a metallic pillar and connected to the temperature regulators (TR1 and TR2) as illustrated in Figure 8A. It is worth to note that the furnace F2 is placed above F1.

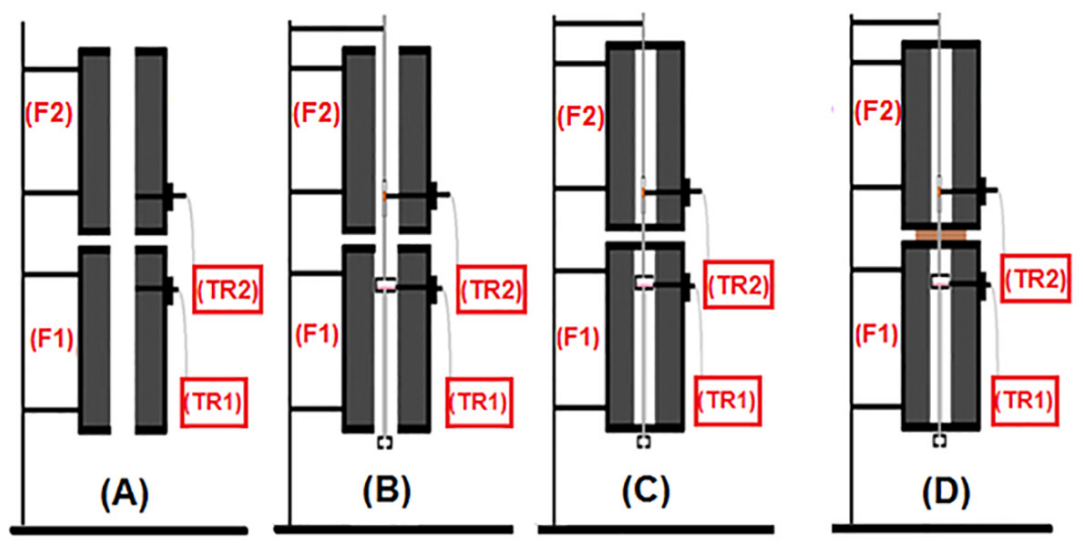

Figure 8. Introduction of the linear reactor inside the furnaces: (A) Open furnaces anchored to a metallic pillar and linked to the temperature regulators, (B) The linear reactor is coaxially placed inside the open furnaces, anchored to the metallic pillar and linked to the thermocouples, (C) The two furnaces F1 and F2 are clogged, and (D) The ceramic cylinder is placed between the two furnaces

Afterwards, the linear reactor R, which contains the salt and the zeolite (Figure 7D), should be coaxially placed inside the two furnaces (previously connected to the thermocouples). The reactor should be softly anchored to the metallic pillar (Figure 8) and the two furnaces should be clogged from each side with quartz wool (Figure 8C) before being separated by a ceramic cylinder (Figure 8D). In reality, the ceramic cylinder is composed of two half-discs and should be drilled in the middle as demonstrated in Figure 9. 


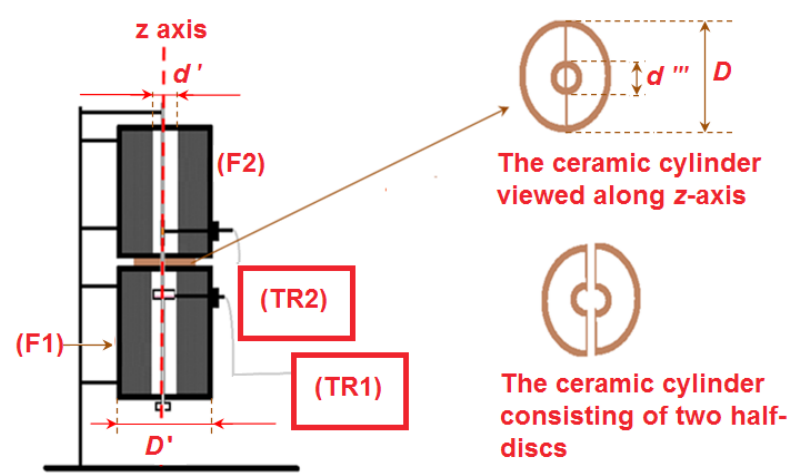

Figure 9. The ceramic cylinder placed between the two furnaces. $D$ and $d^{\prime \prime}$ stands, respectively, for external and internal diameter of the ceramic cylinder, while $D^{\prime}$ and $d^{\prime}$ represents, respectively, the external and internal diameter of the tubular furnace

According to Figure 9: $d^{\prime}<D<D^{\prime}$. Here, $D$ is the diameter of the ceramic cylinder, while $D^{\prime}$ and $d^{\prime}$ stand, respectively, for external and internal diameter of the tubular furnace. Moreover, $d^{\prime \prime}$ should exceed the reactor diameter, denoted as $d^{*}$ in Figure 7A.

\subsubsection{Operating instructions}

At room temperature, the reactor $(\mathrm{R})$, which contains the metallic precursor and the zeolite grains, is placed inside the furnaces (Figure 8). The inlet of the reactor is connected to an inert gas flow, while the outlet is connected to the exhaust as indicated in Figure 6.

The first step of the exchange by sublimation is the zeolite dehydration under a suitable atmosphere (and a desired gas flow). In order to carry out this procedure, the second regulator (TR2) is programmed at a chosen temperature $\left(T_{\text {dehydration }}\right)$ and the furnace F2 is turned on. Following the dehydration of the zeolite under the appropriate atmosphere (at a desired temperature and for a specific time duration), TR2 is fixed at the exchange temperature (either $T_{\text {exch }}<T_{\text {dehyd }}$ or $T_{\text {exch }}>T_{\text {dehvd }}$ ). Once the furnace F2 is heated/cooled to the elected exchange temperature under the desired gas, the fixed bed containing the dehydrated zeolite will be kept at $T_{\text {exch }}$.

The second step of the exchange corresponds to the thermal treatment of the metallic salt under the desired gas stream at the specific sublimation temperature (either $T_{\text {sub }}<T_{\text {exch }}$ or $T_{\text {sub }}>T_{\text {exch }}$ ). Consequently, the first temperature regulator (TR1) is programmed at a chosen $T_{\text {sub }}$ value, while the second furnace (F2) is still turned on. Once the furnace (F1) reaches the sublimation temperature under the selected atmosphere, the carrier gas will transport the gaseous molecules to the zeolite sample, previously maintained at $T_{\text {exch }}$. It is possible to modify $T_{\text {exch }}$ during the sublimation process by maintaining F1 at Tsub, while subsequently heating F2 to $T_{\text {exch }}^{\prime}\left(\neq T_{\text {exch }}\right)$.

The condensation of gaseous molecules at the exit of F1 could be avoided if the residence time between the reactors is decreased. In order to reach this aim, several points are underlined:

- The fritted disc should be placed sufficiently close to the quartz wool plug inside the reactor;

- Each furnace should be placed sufficiently close to the other;

- Due to its high thermal conductivity, helium should be used as carrier gas;

- The carrier gas flow should be increased.

It is worth to note that the exit of reactor could be connected to a mass spectrometer which permits the continuous analysis of gaseous products to enable the exchange mechanism.

\section{Conclusion}

Using conventional methods, we pointed out that the exchange of Cr ions into ZSM-5 zeolites displayed many disadvantages. On the other hand, the exchange of $\mathrm{Cr}$ and Mo by conventional sublimation method displayed several constraints, which are essentially related to the discrepancy between the exchange $\left(T_{\text {exch }}\right)$ and the sublimation $\left(T_{\text {sub }}\right)$ temperature values. In this work, the proposed sublimation set-up would offer a real solution for the introduction of metallic ions into zeolites irrespective of $T_{\text {exch }}$ and $T_{\text {sub }}$ values. The proposed set-up requires two tubular furnaces, two temperature regulators and a linear reactor.

Despite the deep literature research, no similar sublimation set-up was found, and the design presented in this work is a positive step towards a real conception. 


\section{References}

[1] Pérez-Ramirez J, Christensen CH, Egeblad K, et al. Hierarchical zeolites: enhanced utilisation of microporous crystals in catalysis by advances in materials design. Chem Soc Rev. 2008; 37: 2530-2542.

[2] Ferdjaoui NH, El Berrichi FZ, Ayari F. Kaolin-issued zeolite A as efficient adsorbent for bezanyl yellow and nylomine green anionic dyes. Microporous Mesoporous Mater. 2017; 243: 91-101.

[3] Ayari F, Mannei E, Asedegbega-Nieto E, et al. Light hydrocarbons ammoxidation into acetonitrile over Mo-ZSM-5 catalysts: Effect of molybdenum precursor. Microporous Mesoporous Mater. 2017; 241: 246-257.

[4] Ayari F, Mannei E, Asedegbega-Nieto E, et al. Acetonitrile synthesis via ammoxidation: Mo/zeolites catalysts screening. Fine Chem Engin. 2020; 1: 16-30.

[5] Sanhoob MA, Muraza O, Yoshioka M, et al. Lanthanum, cerium, and boron incorporated ZSM-12 zeolites for catalytic cracking of n-hexane. J Anal Appl Pyrolysis. 2018; 129: 231-240.

[6] Ayari F, Charrad R, Asedegbega-Nieto E, et al. Ethane oxidative dehydrogenation over ternary and binary mixtures of alkaline and alkaline earth chlorides supported on zeolites. Microporous Mesoporous Mater. 2017; 250: 65-71.

[7] Abelló S, Montané D. Exploring iron-based multifunctional catalysts for Fischer-Tropsch synthesis: A review. ChemSusChem. 2011; 4: 1538-1556.

[8] Bulánek R, Novoveská K, Wichterlová B. Oxidative dehydrogenation and ammoxidation of ethane and propane over pentasil ring Co-zeolites. Appl Catal A: Gen. 2002; 235: 181-191.

[9] Goodman ED, Dai S, Yang AC, et al. Uniform Pt/Pd bimetallic nanocrystals demonstrate platinum effect on palladium methane combustion activity and stability. ACS Catal. 2017; 7: 4372-4483.

[10] Karge HG. Post-synthesis modification of microporous materials by solid-state reactions. Stud Surf Sci Catal. 1997; 105: 1901-1948.

[11] Townsend RP, Coker E N. Chapter 11, Ion exchange in zeolites. Stud Surf Sci Catal. 2001; 137: 467-524.

[12] Mannei E, Ayari F, Asedegbega-Nieto E, et al. Solid-state ion exchange of molybdenum (VI) acetylacetonate into ZSM-5 zeolite. Thermochim Acta. 2017; 652: 150-159.

[13] Ayari F, Mannei E, Asedegbega-Nieto E, et al. Elucidation of the solid-state ion exchange mechanism of $\mathrm{MoCl}_{5}$ into ZSM-5 zeolite. Thermochim Acta. 2017; 655: 269-277.

[14] Ayari F, Mannei E, Asedegbega-Nieto E, et al. Solid-state ion exchange of ammonium heptamolybdate tetrahydrate into ZSM-5 zeolite. J Therm Anal Calorim. 2018; 131: 1295-1306.

[15] Wang X, Chen HY, Sachtler WMH. Catalytic reduction of $\mathrm{NO}_{\mathrm{x}}$ by hydrocarbons over Co/ZSM-5 catalysts prepared with different methods. Appl Catal B: Environ. 2000; 26: L227-L239.

[16] Schwartz V, Prins R, Wang X, et al. Characterization by EXAFS of Co/MFI catalysts prepared by sublimation. $J$ Phys Chem B. 2002; 106: 7210-7217.

[17] Marturano P, Drozdová L, Kogelbauer A, et al. Fe/ZSM-5 prepared by sublimation of $\mathrm{FeCl}_{3}$ : The structure of the $\mathrm{Fe}$ species as determined by IR, ${ }^{27} \mathrm{Al}$ MAS NMR, and EXAFS spectroscopy. $J$ Catal. 2000; 192: 236-247.

[18] Delahay G, Guzmfin-Vargas A, Valade D, et al. Selective catalytic reduction of $\mathrm{NO}$ by $\mathrm{NH}_{3}$ on Fe-ZSM-5 elaborated from different methods. Stud Surf Sci Catal. 2004; 154: 2501-2508.

[19] Spoto G, Zecchina A, Bordiga S, et al. Cu(I)-ZSM-5 zeolites prepared by reaction of H-ZSM-5 with gaseous CuCl: Spectroscopic characterization and reactivity towards carbon monoxide and nitric oxide. Appl Catal B: Environ. 1994; 3: $151-172$.

[20] Sen D, Heo NH, Kang HC, et al. Using InCl vapor to ion exchange indium into zeolite Na-Y. Single-crystal structure of $\left|\mathrm{In}_{25.8} \mathrm{Cl}_{0.8} \mathrm{Na}_{37.0}\right|\left[\mathrm{Si}_{121} \mathrm{Al}_{71} \mathrm{O}_{384}\right]$-FAU containing $\mathrm{In}^{+}, \mathrm{In}^{3+}$, and $\mathrm{In}_{5}{ }^{7+}-\mathrm{Cl}^{-}-\mathrm{In}_{5}{ }^{7+} . J$ Phys Chem C. 2011; 115: 2347023479.

[21] Ayari F, Mannei E, Asedegbega-Nieto E, et al. Catalytic behaviour of molybdenum-based zeolitic materials prepared by organic-medium impregnation and sublimation methods. J Iran Chem Soc. 2020; 17: 1087-1101.

[22] Ayari F, Mannei E, Asedegbega-Nieto E. Thermal properties of molybdenum hexacarbonyl: Kinetic and thermodynamic studies. $J$ Chem Thermodyn. 2020; In progress.

[23] Pierson HO. Handbook of chemical vapor deposition. Park Ridge (NJ): Noyes; 1992.

[24] Jones AC, Hitchman ML (Ed). Chemical Vapour Deposition: Precursors, Processes and Applications. Royal Society of Chemistry; 2009.

[25] Blocher JM. Structure/property/process relationships in chemical vapor deposition CVD. J Vac Sci Technol. 1974; 11: 680-686.

[26] Choy KL. Chemical vapour deposition of coatings. Prog Mater Sci. 2003; 48: 57-170.

[27] Krishna K, Seijger GBF, van den Bleek CM, et al. Selective catalytic reduction of NO with $\mathrm{NH}_{3}$ over Fe-ZSM-5 catalysts prepared by sublimation of $\mathrm{FeCl}_{3}$ at different temperatures, Catal. Lett. 2003; 86: 121-132.

[28] Harjula R, Dyer A, Pearson SD, et al. Ion exchange in zeolites. Part 1. Prediction of $\mathrm{Ca}^{2+}-\mathrm{Na}^{+}$equilibria in zeolites X 
and Y. J Chem Soc, Faraday Trans. 1992; 88: 1591-1597.

[29] Harjula R, Dyer A, Townsend RP. Ion exchange in zeolites. Part 3. Hydrolysis and trace ${ }^{45} \mathrm{Ca}^{2+}$ and ${ }^{22} \mathrm{Na}^{+}$exchanges in zeolites X and Y. J Chem Soc, Faraday Trans. 1993; 89: 977-981.

[30] Harjula R, Lehto J, Pothuis JH, et al. Ion exchange in zeolites. Part 4. Hydrolysis and trace ${ }^{134} \mathrm{Cs}^{+}$exchange in K- and Na-mordenite. J Chem Soc, Faraday Trans. 1993; 89: 1877-1882.

[31] Mattigod SV, Rai D, Felmy AR, et al. Solubility and solubility product of crystalline $\mathrm{Ni}(\mathrm{OH})_{2}$. J Solution Chem. 1997; 6: 391-403.

[32] Zemaitis Jr JF, Clark DM, Rafal M, et al. Handbook of Aqueous Electrolyte Thermodynamics. American Institute of Chemical Engineers, New York; 1986.

[33] Ayari F, Mhamdi M, Álvarez-Rodríguez J, et al. Selective catalytic reduction of NO with $\mathrm{NH}_{3}$ over Cr-ZSM-5 catalysts: General characterization and catalysts screening. Appl Catal B: Environ. 2013; 134-135: 367-380. 